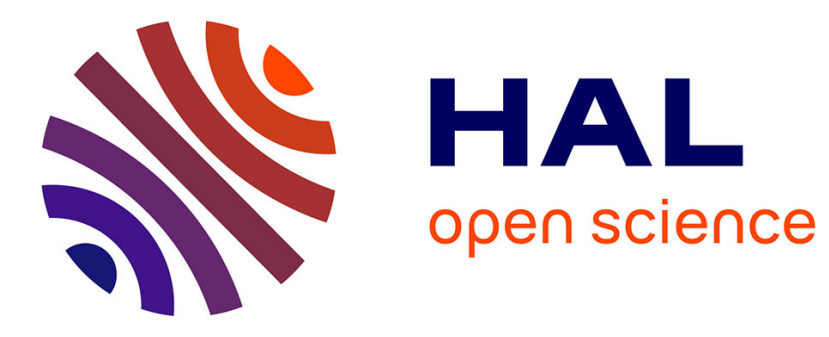

\title{
Ultradispersed (Co)Mo catalysts with high hydrodesulfurization activity
}

Daria Ryaboshapka, Laurent Piccolo, Mimoun Aouine, Pascal Bargiela, Valérie Briois, Pavel Afanasiev

\section{- To cite this version:}

Daria Ryaboshapka, Laurent Piccolo, Mimoun Aouine, Pascal Bargiela, Valérie Briois, et al.. Ultradispersed (Co)Mo catalysts with high hydrodesulfurization activity. Applied Catalysis B: Environmental, 2022, 302, pp.120831. 10.1016/j.apcatb.2021.120831 . hal-03439551

\section{HAL Id: hal-03439551 \\ https://hal.science/hal-03439551}

Submitted on 22 Nov 2021

HAL is a multi-disciplinary open access archive for the deposit and dissemination of scientific research documents, whether they are published or not. The documents may come from teaching and research institutions in France or abroad, or from public or private research centers.
L'archive ouverte pluridisciplinaire HAL, est destinée au dépôt et à la diffusion de documents scientifiques de niveau recherche, publiés ou non, émanant des établissements d'enseignement et de recherche français ou étrangers, des laboratoires publics ou privés. 


\title{
Ultradispersed (Co)Mo catalysts with high hydrodesulfurization activity
}

Daria Ryaboshapka ${ }^{1}$, Laurent Piccolo ${ }^{1}$, Mimoun Aouine ${ }^{1}$, Pascal Bargiela ${ }^{1}$, Valérie Briois ${ }^{2}$, Pavel Afanasiev ${ }^{1}$.

${ }^{1}$ Institut de Recherches sur la Catalyse et l'Environnement de Lyon (IRCELYON), Univ Lyon, CNRS, Université Claude Bernard Lyon 1, 2 avenue A. Einstein, 69626 Villeurbanne, France

${ }^{2}$ SOLEIL synchrotron, UR1-CNRS, L’Orme des Merisiers, BP48, 91192 Gif-sur-Yvette, France

\begin{abstract}
In spite of the huge worldwide interest for single-atom and ultradispersed catalysts, metal atoms coordinated with sulfur are rarely addressed. In this work, ultradispersed molybdenum-based catalysts were obtained by adsorption of three thiomolybdates of different nuclearity $(n=1,2,3)$ on high-surface-area S-doped carbon, followed by sulfidation in $\mathrm{H}_{2} \mathrm{~S} / \mathrm{H}_{2}$ flow at $350{ }^{\circ} \mathrm{C}$. Scanning transmission electron microscopy (STEM) and X-ray absorption spectroscopy (XAS) attest that single atoms and few-atom clusters are predominant on the surface of the materials after adsorption, as well as after sulfidation and thiophene HDS reaction. Independently on the nature of the thiomolybdate precursor, sulfidation leads to catalysts with specific thiophene HDS activity exceeding that of a conventional supported $\mathrm{MoS}_{2}$ reference. Ultradispersed clusters were further promoted with cobalt, yielding HDS turnover frequencies 2-3 times higher than those of reported benchmark CoMoS catalysts. These findings provide new insights into the previously debated issues of structure-activity relationships for HDS catalysts and expand the range of applications of atomically dispersed catalysts.
\end{abstract}

\section{Introduction}

One of the main challenges in sustainable development and energy transition is the design of more active and selective heterogeneous catalysts [1,2]. Among the existing strategies, the recently emerged concept of single-atom (SA) catalysis occupies an important 
place $[3,4,5]$. With the advent of new characterization tools such as aberration-corrected scanning transmission electron microscopy-high angle annular dark field (STEM-HAADF) and operando X-ray Absorption Spectroscopy (XAS), small structures that were impossible to observe before might be recognized now $[6,7,8]$. The catalytic performance of single-atom catalysts (SACs) is widely investigated in the reactions involving $\mathrm{H}_{2}$, such as hydrogen evolution reaction (HER) [9,10], oxygen reduction reaction (ORR) [11], and hydrogenation [12]. However, these catalysts often contain expensive platinum-group metals as active components. The latter might be replaced by cheaper transition-metal (TM) compounds. Among non-noble TMs, molybdenum compounds are extensively applied in catalysis due to the versatility of Mo coordination and oxidation states, in various forms, including oxides, nitrides, carbides, and sulfides $[13,14,15,16]$. In particular, molybdenum disulfide $\mathrm{MoS}_{2}$ is recognized as an inexpensive alternative electrocatalyst for HER catalysis and photoelectrochemical water splitting $[17,18,19]$. $\mathrm{MoS}_{2}$ is also well-known as an active phase for hydrotreating, which is an important industrial process involving removal of heteroatoms $(\mathrm{S}, \mathrm{O}, \mathrm{N}$, metals) from petroleum in refineries [20, 21, 22]. Despite the great general importance of molybdenum in catalysis, for now there are only few reports investigating Mo SACs. Recently, it was shown that Mo SAs on carbonaceous supports doped with heteroatoms possess significant catalytic activity and stability in ORR [23, 24]. However, very few studies currently exist on the sulfur-bearing Mo SAs or small clusters in heterogeneous catalytic reactions, and in particular in the reactions involving hydrogen, such as hydrodesulfurization (HDS) [25].

In conventional heterogeneous catalysts, Mo disulfide nanoparticles are usually supported on an oxide such as $\gamma$-alumina, and doped with promoters $(\mathrm{Ni}, \mathrm{Co})[20,26]$. The catalytic sites are considered to be located at the edges of hexagonal and triangular $\mathrm{MoS}_{2}$ particles, exposing chemically distinct edges (so-called S- and Mo- edges) [27]. In the cobaltpromoted catalysts, Co atoms are believed to substitute Mo atoms at the S-edges, forming socalled "CoMoS" structures $[28,29]$. To improve the catalytic performance of $\mathrm{MoS}_{2}$ systems, the amount of exposed edges should be maximized and therefore highly dispersed $\mathrm{MoS}_{2}$ slabs should be prepared. This goal was achieved via different approaches such as special preparation techniques [30], engineering of support properties [31], or use of organic additives [32, 33]. In such catalysts, along with typical hexagonal/triangular structures, very small clusters of several atoms or even single Mo atoms might be present. The current paradigm attributes catalytic activity merely to the edges of $\mathrm{MoS}_{2}$ slabs but does not focus on these small structures. The observed differences of activity are explained by variations in the geometry of slabs as well as by differences in chemical state of the edges [34, 35]. However, some experimental 
observations could hardly be explained on the basis of this view. For example, the evolution of HDS activity vs. the preparation temperature could not be explained by only slight variations of slabs size and shape as observed by conventional TEM [36]. In several recent papers studying highly dispersed $\mathrm{MoS}_{2}$-based catalysts, clusters of several atoms or even single heavy atoms could be clearly seen in the STEM-HAADF images [31, 33, 37]. Such ultra-small species coexist as a minor component with extended (several $\mathrm{nm}$ size) $\mathrm{MoS}_{2}$ slabs, and their role in the catalytic activity was never assessed.

In this work, we elaborated and characterized Mo-based catalysts containing few-atom clusters and single atoms as major Mo species. The catalytic behavior of such ultradispersed sulfur-bearing species in thiophene HDS was studied and compared with a conventional $\mathrm{MoS}_{2} / \mathrm{Al}_{2} \mathrm{O}_{3}$ catalyst.

\section{Experimental}

\section{Catalysts preparation}

All reactants and solvents were high-purity-grade products purchased from Sigma Aldrich. Activated charcoal Norit (further referred to as activated carbon, AC) was used as the support. To remove possible metallic impurities, it was thoroughly washed with concentrated

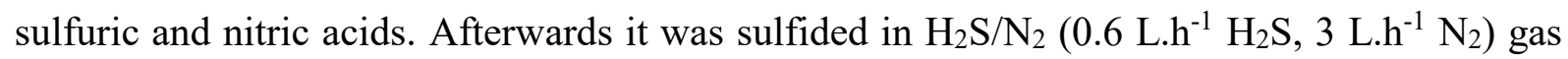
mixture for $3 \mathrm{~h}$ at $750{ }^{\circ} \mathrm{C}$. The heating rate was $10{ }^{\circ} \mathrm{C} \cdot \mathrm{min}^{-1}$ and the $\mathrm{AC}$ mass $4 \mathrm{~g}$. As a result, an AC doped with sulfur (S-AC) support was obtained.

Three thiomolybdates were used as the precursors: monomeric $\left(\mathrm{NH}_{4}\right)_{2} \mathrm{MoS}_{4}$, dimeric $\left(\mathrm{NH}_{4}\right)_{2} \mathrm{Mo}_{2} \mathrm{~S}_{12}$, and trimeric $\left(\mathrm{NH}_{4}\right)_{2} \mathrm{Mo}_{3} \mathrm{~S}_{13}$, prepared according to the methods described in Refs. [38, 39, 40]. Earlier, it was stated that AC is a good adsorbent for thiomolybdates [41]. Three catalysts were prepared via the equilibrium adsorption route. A weighted amount of a thiomolybdate precursor was dissolved in methanol or DMF (in the case of the trimer, which is poorly soluble in methanol), then added to a suspension of S-AC in methanol (or DMF) and stirred overnight. The samples were then filtered in air and dried in inert atmosphere. The sample obtained from the trimer was first washed with small amounts of methanol and then filtered and dried.

All samples were sulfided in a quartz reactor in $\mathrm{H}_{2} \mathrm{~S} / \mathrm{H}_{2}\left(0.6 \mathrm{~L} \cdot \mathrm{h}^{-1} \mathrm{H}_{2} \mathrm{~S}, 3 \mathrm{~L} \cdot \mathrm{h}^{-1} \mathrm{H}_{2}\right)$ gas mixture at $350{ }^{\circ} \mathrm{C}$ for $1 \mathrm{~h}$. The samples were heated at $5{ }^{\circ} \mathrm{C} \cdot \mathrm{min}^{-1}$ rate. Then, the $\mathrm{H}_{2} \mathrm{~S}$ flow was 
turned off and the samples were cooled to room temperature in a $1.8 \mathrm{~L}^{-1} \mathrm{~h}^{-1}$ flow of $\mathrm{H}_{2}$. For comparative reasons, a sample sulfided in pure $\mathrm{H}_{2} \mathrm{~S}$ was also prepared.

The cobalt-promoted samples were prepared via the equilibrium adsorption route described earlier [42]. In brief, a weighted amount of Co (II) acetylacetonate was dissolved in methanol, flushed with nitrogen, and then a weighted amount of a sulfided Mo sample powder was added. The mixture was stirred at $65^{\circ} \mathrm{C}$ for $4 \mathrm{~h}$, then filtered and dried in inert atmosphere. To prepare a reference sample containing solely $\mathrm{Co}, \mathrm{S}-\mathrm{AC}$ was added to the solution of Co acetylacetonate, and then the sample was treated in the same conditions as the Co-Mo samples. After adsorption and sulfidation-reduction, all samples were kept under inert atmosphere.

The samples are named according to the nuclearity of the used thiomolybdates and their treatment conditions: Mo1, Mo2 and Mo3 stand for monomer, dimer and trimer-derived solids, respectively, while INIT, SULF and HDS are used to designate the initial, sulfided, and postHDS catalysts, respectively. The sample sulfided in pure $\mathrm{H}_{2} \mathrm{~S}$ is designated as Mo1-SULF $\left(\mathrm{H}_{2} \mathrm{~S}\right)$ For cobalt-promoted systems, a Co- prefix is added. Thus, for example, a cobalt-promoted sample prepared using $\left(\mathrm{NH}_{4}\right)_{2} \mathrm{MoS}_{4}$ and taken after catalytic test is designated as Co-Mo1-HDS.

Supported containing $10 \%$ wt. of Mo was prepared by incipient dry

\section{Thiophene HDS test}

The samples were tested in thiophene HDS after sulfidation in $\mathrm{H}_{2} \mathrm{~S} / \mathrm{H}_{2}$ at $350{ }^{\circ} \mathrm{C}$. Approximately $250 \mathrm{mg}$ of sulfided sample was placed in a flow fixed-bed quartz microreactor. A $3 \mathrm{~L}^{-1} \mathrm{~h}^{-1} \mathrm{H}_{2}$ flow passed through the bubbler containing thiophene, which was kept in a thermostat at $0{ }^{\circ} \mathrm{C}$. The reaction was performed at atmospheric pressure in a temperature range of $320-340{ }^{\circ} \mathrm{C}$, at a heating rate of $5{ }^{\circ} \mathrm{C} \cdot \mathrm{min}^{-1}$. The steady-state conversions were obtained after at least 16 hours on-stream. Three temperatures were used: 320,330 , and $340^{\circ} \mathrm{C}$. The reaction products were analyzed by gas chromatography on an Agilent 7820A device equipped with a flame ionization detector.

HDS specific rates were estimated according to equation:

$$
r=-\left(\frac{F_{\text {thio }}}{m}\right) \times \operatorname{Ln}(1-x)
$$

$\mathrm{F}_{\text {thio }}$ - thiophene molar flow $\left(\mathrm{mol} . \mathrm{s}^{-1}\right), \mathrm{m}$ - mass of the catalyst $(\mathrm{g}), \mathrm{x}$ - thiophene conversion. TOF (turnover frequency) values of the catalysts were calculated via following equation: 


$$
T O F=\frac{r \times N_{A}}{N}
$$

$\mathrm{r}$ - specific HDS rate (mol.g $\left.\mathrm{g}^{-1} \mathrm{~s}^{-1}\right), \mathrm{N}_{\mathrm{A}}$ - Avogadro number, $\mathrm{N}$ - number of Mo atoms per gram of the catalyst.

\section{Characterization techniques}

The amount of Mo in the initial samples (after adsorption) was quantified by inductively coupled plasma-optical emission spectroscopy (ICP-OES, Activa instrument from Horiba Jobin Yvon). The catalysts were treated with a mixture of $\mathrm{H}_{2} \mathrm{SO}_{4}$ and $\mathrm{HNO}_{3}$ at $250-300{ }^{\circ} \mathrm{C}$ before analysis. The quantities of light elements $(\mathrm{C}, \mathrm{N}, \mathrm{S})$ were analyzed on a Thermo Fisher Flash 2000. Approximately $1 \mathrm{mg}$ of each sample was placed in a tin capsule with addition of a small amount of $\mathrm{V}_{2} \mathrm{O}_{5}$. The capsule was placed inside the autosampler and then dropped into the reactor where combustion was performed. The obtained gases were analyzed by a gas chromatograph equipped with a thermal conductivity detector. For each sample, the analysis was performed two times.

Specific surface area and porosity of the S-AC support and selected initial and sulfided samples were studied by $\mathrm{N}_{2}$ adsorption-desorption at $-196{ }^{\circ} \mathrm{C}$ on a Micrometrics ASAP 2010 device. Specific surface areas and pore size distributions were determined using the BET and BJH equations, respectively. Prior to the measurements, the samples were outgassed at $350{ }^{\circ} \mathrm{C}$ for $3 \mathrm{~h}$. X-ray diffraction (XRD) patterns were recorded on a Bruker D8 Advance A25 diffractometer with $\mathrm{Cu} \mathrm{K} \alpha$ emission. The diffractograms of the S-AC support and the sulfided samples were collected at $2 \theta$ from 4 to $70^{\circ}$ with a step of $0.02^{\circ}$. The phases present in the samples were identified using the JCPDS database. Raman spectra were obtained on a LabRam HR spectrometer (Horiba-Jobin Yvon). An Ar laser ( $\lambda=514.5 \mathrm{~nm}$, power $1 \mathrm{~mW}$ ) was used as the excitation source. The spectra were recorded with a resolution of $4 \mathrm{~cm}^{-1}$. Transmission electron microscopy (TEM) was performed on a JEOL 2010 instrument equipped with a $\mathrm{LaB}_{6}$ filament at an accelerating voltage of $200 \mathrm{kV}$. STEM-HAADF was carried out on a FEI Titan G2 aberration-corrected environmental TEM at $300 \mathrm{kV}$ voltage. To prepare the samples for microscopy, the catalysts were crushed in an agate mortar with addition of a small amount of ethanol, and treated in ultrasonic bath. The obtained suspensions were dropped on a holey carbon-covered copper grid and dried. The obtained microphotographs were analyzed with the Digital Micrograph Gatan program package. 
The local structure of Mo species was investigated by X-ray absorption spectroscopy (XAS) in transmission mode on the ROCK beamline at the SOLEIL synchrotron [43]. X-ray absorption spectra at the Mo K edge were recorded using a Si(220) channel-cut monochromator. The samples were placed without air contact in argon atmosphere in plastic sample holders and protected with a double Kapton scotch layer. Prior to measurements, the samples were handled in Ar-filled sealed plastic bags. Data merging, alignment and preliminary analysis as well as linear combination fitting and principal component analysis were carried out using the ATHENA software [44]. For alignement, the first inflection point of MoK edge was placed at 20000.0 eV. Extended X-ray Absorption Fine Structure (EXAFS) spectra were fitted using the VIPER program [45], alternatively in $k$ and $R$ spaces. For the $R$ space, it was done in the (Im + Module) mode.

X-ray photoelectron spectroscopy (XPS) was carried out on a Kratos Axis Ultra DLD spectrometer, using as $\mathrm{X}$-ray source the monochromatic $\mathrm{Al} \mathrm{K \alpha}$ radiation (1486.6 eV), operating at $225 \mathrm{~W}, 15 \mathrm{kV}, 15 \mathrm{~mA}$. Prior to the experiment the samples were crushed into powder and pressed onto conductive carbon tape under argon atmosphere. The survey spectra were registered in interval $1200-0 \mathrm{eV}$ with a pass energy of $160 \mathrm{eV}$. High-resolution spectra, pass energy of $40 \mathrm{eV}$, were obtained for $\mathrm{O} 1 \mathrm{~s}, \mathrm{~N} 1 \mathrm{~s}, \mathrm{Mo} 3 \mathrm{~d}+\mathrm{S} 2 \mathrm{~s}, \mathrm{C} 1 \mathrm{~s}$ and $\mathrm{S} 2 \mathrm{p}$ regions. XPS spectra were treated with CasaXPS software. For spectra alignment, C 1s photoemission peak of graphite support ( $\mathrm{sp}^{2}$ carbon) located at $284.5 \mathrm{eV}$ was used.

\section{Results and discussion}

\subsection{Routine characterizations and electron microscopy}

Preparation of ultradispersed catalysts is often considered to be a difficult task due to high free surface energy of single atoms and their tendency to aggregate [46, 47, 48]. Here we propose a simple preparation route via equilibrium adsorption of thiomolybdates on the surface of a suitable support. While considering the choice of the support, interaction between the Mo species and the surface groups of this support must be considered. On the oxidic supports such as alumina and at low Mo loadings, a strong interaction might occur that leads to stabilization of oxygen-coordinated Mo species (molybdates or polymolybdates) with low HDS activity [49].

AC seems to have an advantage since its surface is rather inert, it is thermally stable and provides high surface area and porosity required for catalytic applications. Moreover, its low atomic weight facilitates observation of TM atoms hosted on its surface by means of STEM. 
Stabilization of single atoms/few-atom clusters at the surface of carbon often requires functionalization with heteroatoms such as $\mathrm{N}, \mathrm{O}$, or $\mathrm{S}[50,51]$. To prepare sulfide TM clusters, the use of sulfur-doped carbons seems a natural choice. We initially hypothesized that a large excess of sulfur on the surface will would improve stability of the sulfided forms of molybdenum preventing their oxidation (vide infra). A variety of strategies for bulk and surface doping of carbonaceous supports with sulfur exists in the literature [52]. A simple treatment of $\mathrm{AC}$ in $\mathrm{H}_{2} \mathrm{~S}$ at elevated temperature allowed us to introduce $8.4 \mathrm{wt} \% \mathrm{~S}$ (Table $\mathrm{S} 1$ ). The $\mathrm{S}-\mathrm{AC}$ as obtained has specific a surface area of $642 \mathrm{~m}^{2} / \mathrm{g}$ and a pore volume (BJH) of $0.47 \mathrm{~cm}^{3} / \mathrm{g}$. After adsorption of thiomolybdates, the specific surface areas only slightly decrease (Table S2). According to ICP, all three samples contain nearly $0.5 \mathrm{wt} \%$ Mo.

Conventional TEM images do not show the presence of $\mathrm{MoS}_{2}$ or $\mathrm{CoS}_{\mathrm{x}}$ nanoparticles, or other condensed Mo- or Co-containing phases in all the studied materials. Only the graphite layered framework could be seen by TEM (Fig. S2). In line with TEM results, XRD did not reveal the presence of any crystalline Mo-containing phases (Fig. S3). The same conclusion was inferred from the Raman spectroscopy data: the spectra of Mo-containing samples were identical to the spectrum of S-AC. Only two intense bands were observed at $1321 \mathrm{~cm}^{-1}$ and $1598 \mathrm{~cm}^{-1}$, which correspond to so-called D and G lines, respectively, typical for defective carbon structures [53] (Fig. S4). Thus, we supposed that Mo species in our materials might be present in an ultradispersed state.

To confirm the presence of ultradispersed Mo species, the sulfided samples Mo1-SULF, Mo2-SULF, Mo3-SULF were analyzed by means of STEM-HAADF. On the micrographs, numerous single dots (approximately $0.3 \mathrm{~nm}$ in size) and agglomerates of several dots are present (Fig. 1), corresponding to Mo SAs and few-atom clusters, respectively. 

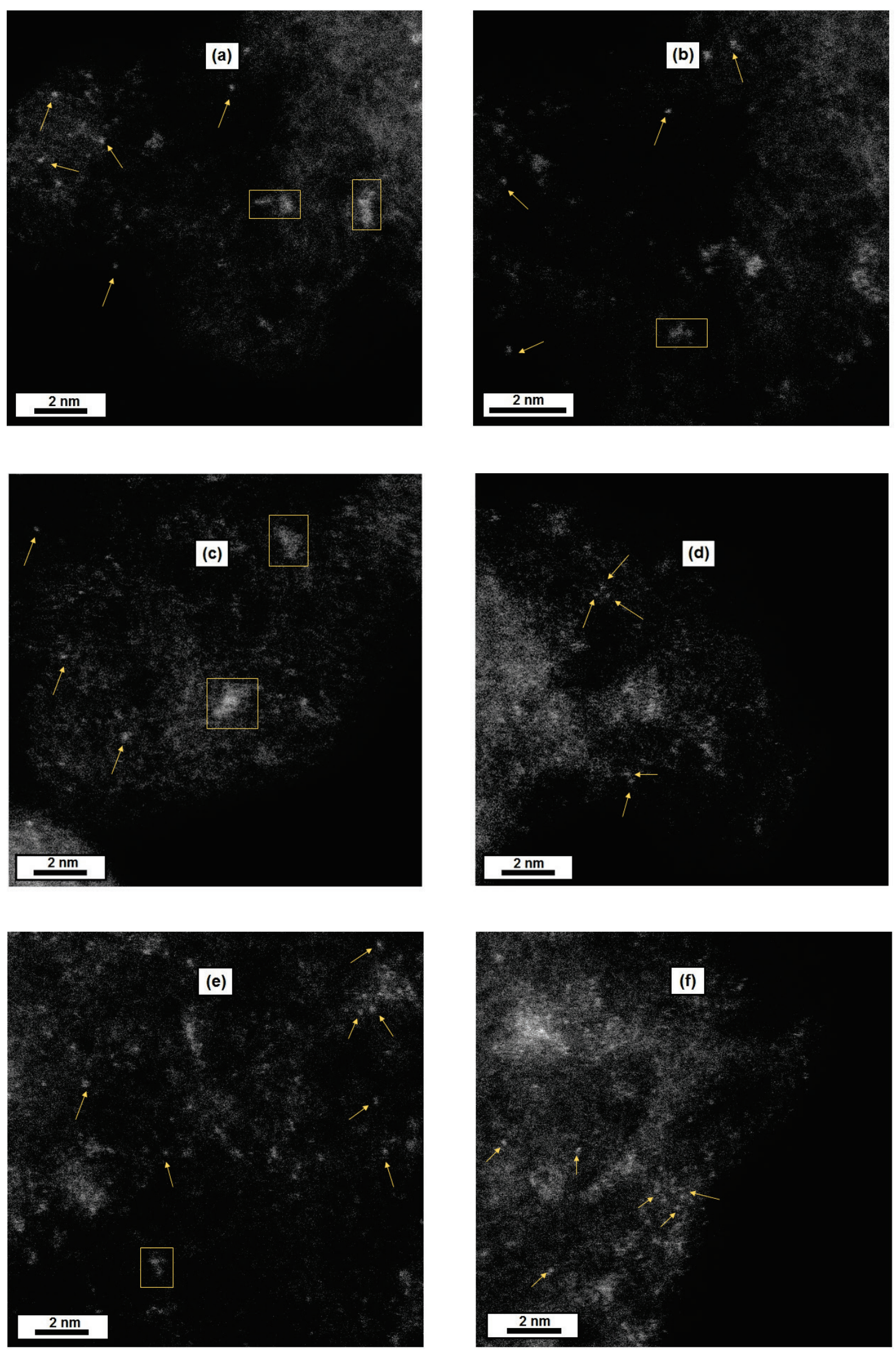

Figure 1 STEM-HAADF images of (a-b) Mo1-SULF, (c-d) Mo2-SULF, and (e-f) Mo3-SULF. 
Although several $\mathrm{MoS}_{2}$ slabs are visible on the images of Mo3-SULF, their amount seems negligible when compared with the amount of ultradispersed species. The results of STEM thus suggest that molybdenum is mostly present in the atomically dispersed state, either in the SA or few-atom cluster state.

\subsection{XAS analysis}

From the characterizations as presented above, it remains unclear whether the Mo species are coordinated with sulfur (as they are in the parent thioanions), or whether they evolve toward another chemical state. For such ultradispersed non-crystalline systems, XAS is among the few techniques suitable to access the coordination and the oxidation state of TMs. Nine samples have been characterized by XAS, including initial and sulfided solids and the samples taken after HDS test. X-ray absorption near edge structure (XANES) spectra are shown in Fig. 2a, c, e and in Fig. S5. The initial samples Mo1-INIT and Mo2-INIT show a considerable preedge feature, whereas for the Mo3-INIT solid as well as the solids after sulfidation or HDS test, this feature is weaker and merges with the main jump (Fig. 2). The presence of a pre-edge is characteristic for tetrahedral or other non-centrosymmetric coordination geometries that allow quadrupole 1s-4d transitions [54]. Notably, XANES spectra of Mo1-INIT and Mo2-INIT bear considerable similarity with the previously studied soluble "Mo-blue" oxospecies produced by $\mathrm{MoS}_{2}$ oxidation in ambient air (Fig. S5b). These oxospecies contain mostly Mo(V)-Mo(VI) dimers, as reported in Ref. [55].

The common XANES plot for all nine samples (Fig. S5a) demonstrates approximate isosbestic points, suggesting that few Mo species in different proportions coexist in the materials (two main species and some minor ones that explain small deviations from the isoabsorption). To estimate more rigorously the possible number of species, principal component analysis (PCA) was carried out for the set of nine XANES spectra. PCA results show rapidly decreasing eigenvalues with a Scree plot suggesting that most of the variance contained in the XANES spectra set can be explained by 2 eigenvectors (Fig. S6). The first eigenvector PC1 expectedly reproduces the general shape of the XANES plot, whereas the second one represents variations between the spectra. All the following eigenvectors correspond to measurement noise accounting for $c a \cdot 10^{-3} \%$ of variance. Noteworthy, the general shape of PC1 looks very similar to the one reported for Mo-based oxidic species displaying a marked pre-edge feature in the rising edge (Fig. S5b). The additional feature characterizing PC2 does 
not contain the pre-edge feature as expected for Mo-based fully sulfidic species [56, 57]. Linear combination fitting (LCF) was tried to describe the XANES spectra, using as standards several potentially relevant oxide and sulfide materials. For Mo1-INIT and Mo2-INIT samples, the combinatorial LCF procedure rejected all available sulfur-containing standards (bulk $\mathrm{MoS}_{2}$, $\mathrm{MoS}_{3}$, and all thiomolybdates) but required a considerable contribution of the "Mo-blue" [55], and/or of oxygen-coordinated dimolybdate anions (Table S3). Therefore, XANES suggests that instead of the initial thioanions, oxidized species are present in Mo1-INIT and Mo2-INIT solids. Oxidation (and dimerization for $\left.\left(\mathrm{NH}_{4}\right)_{2} \mathrm{MoS}_{4}\right)$ could occur during the adsorption procedure or during filtration, both carried out in air.

For the Mo3-INIT solid and for all samples studied after sulfidation or HDS test, the LCF indicated the presence of sulfur-containing species, such as oxothiomolybdate $\left(\mathrm{NH}_{4}\right)_{2} \mathrm{MoO}_{2} \mathrm{~S}_{2}$ or thiotrimolybdate $\left(\mathrm{NH}_{4}\right)_{2} \mathrm{Mo}_{3} \mathrm{~S}_{13}$ (Tables S3 and S4). Notably, bulk MoS 2 has been rejected in all instances. In the sulfided solids and in the samples after HDS, the main jump energy expectedly shifts towards lower values (Fig. 2), in agreement with the earlier observed difference between oxide and sulfide species [55]. The LCF approach for XANES spectra is limited because the conclusions drawn from LCF fitting depend on the successful guess of standard compounds, and because variance is mainly limited to the position of the rising edge. However, the ensemble LCF and PCA analyses converge to the conclusion that all samples contain oxide and sulfide species with similar XANES profiles, whereas no significant contribution from bulk $\mathrm{MoS}_{2}$ could be identified.

EXAFS spectra have been fitted using three or four shells that include one or two MoO shells, one Mo-S shell and one Mo-Mo (Table 1, Figs 2b, d, f, S7-S8). The three initial samples show different Mo coordination environment, depending on the used precursor. EXAFS attests that in both Mo1-INIT and Mo2-INIT, Mo atoms are coordinated with oxygen (a short $\mathrm{Mo}=\mathrm{O}$ bond at 1.69-1.72 $\AA$ and a long Mo-O one at $1.94 \AA$ ) and molybdenum (3.243.30 Å distance, corresponding to a Mo-O-Mo fragment, Table 1). Summation of coordination numbers of light neighbors gives overall $\mathrm{CN}$ near four, corresponding probably to the tetrahedral coordination. Therefore, in agreement with XANES results, the initial mono- and di- thiomolybdates have been deeply transformed during the preparation. For the Mo3-INIT sample a considerable amount of sulfur is present in the coordination sphere of molybdenum, and Mo-Mo distance of $2.73 \AA$ is present, corresponding to the Mo-S-Mo fragment of $\mathrm{Mo}_{3} \mathrm{~S}_{13}{ }^{2-}$ ion and indicating higher stability of the thiotrimolybdate species on the S-AC support.

After treatment in $\mathrm{H}_{2} \mathrm{~S} / \mathrm{H}_{2}$, sulfur expectedly appears in the coordination sphere of molybdenum for Mo1 and Mo2 (and preserved for Mo3), but a considerable amount of oxygen 
still remains in it for all three samples. Hence, unlike highly loaded conventional catalysts where $\mathrm{MoS}_{2}$ slabs are formed, ultradispersed species are not fully transformed to sulfide under the conditions applied. At the same time, the number of Mo-Mo neighbors decreases after sulfidation. This suggests cleavage of oligomers and formation of single atoms in agreement with STEM of sulfided samples. For the Mo3 solid, the Mo-Mo distance at $3.16 \AA$ appears, corresponding to $\mathrm{MoS}_{2}$, but not in the Mo1 and Mo2 samples. After the HDS test, the amount of sulfur in the Mo coordination sphere further increases for Mo1-HDS and Mo3-HDS solids, whereas the number of Mo-Mo neighbors does not change significantly, indicating that no considerable agglomeration occurred during the catalytic reaction (in case of Mo2-HDS, the Mo-O-Mo distance at $3.28 \AA \AA$ reappears after reaction, due to partial re-oxidation caused by a technical problem). 
(a)

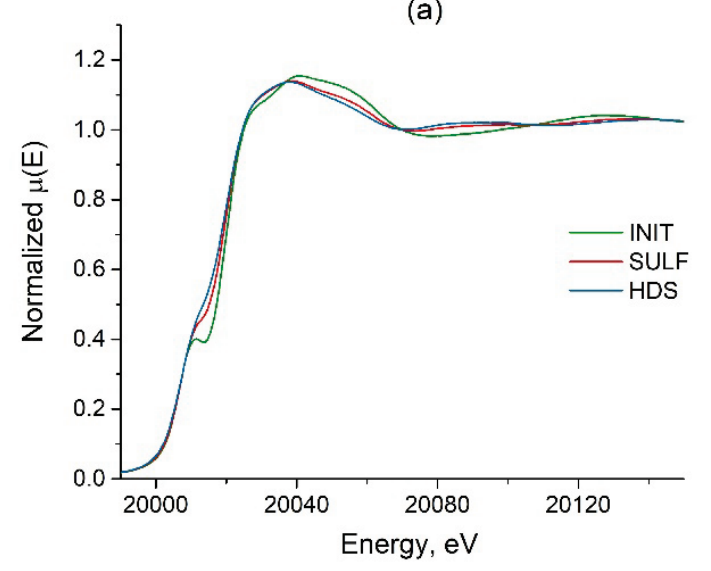

(c)

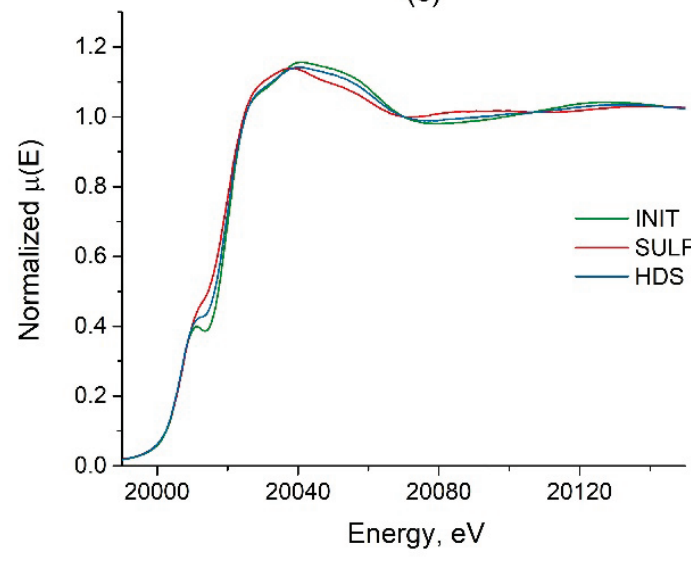

(e)

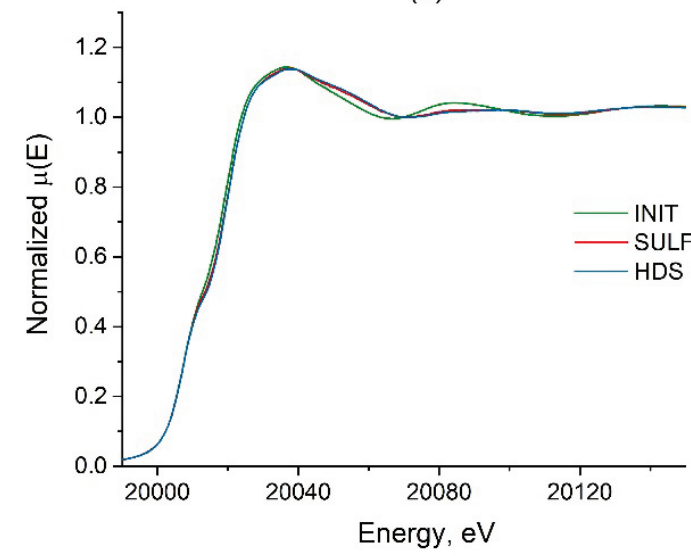

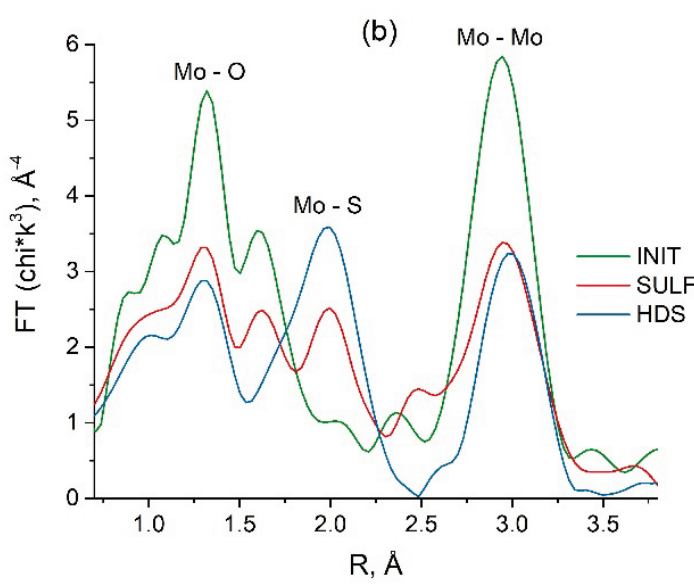

(d)

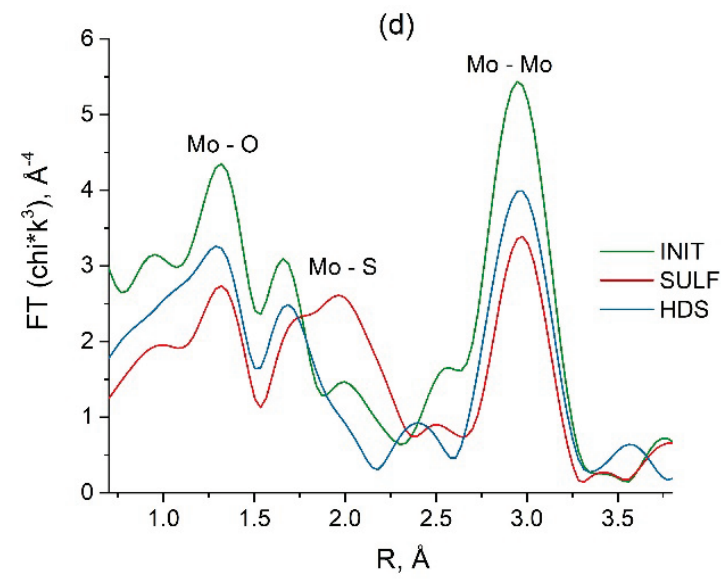

(f)

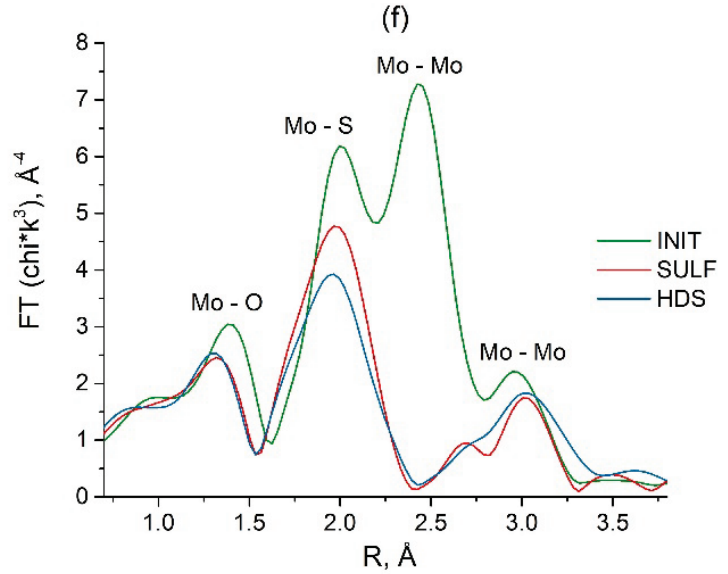

Figure 2 (a, c, e) XANES curves for initial, sulfided, and post-HDS Mo1 (a), Mo2 (c), and Mo3 (e) samples. (b, d, f) FT of $k^{3}$. $\square(k)$ EXAFS curves ( $k$ from 3 to $15 \AA^{-1}$ ) for the initial, sulfided and post-HDS Mo1 (b), Mo2 (d) and Mo3 (f) samples. 
Table 1 XAS fitting results.

\begin{tabular}{|c|c|c|c|c|}
\hline $\begin{array}{c}\text { Scatterer } \\
\text { atom }\end{array}$ & $C N^{a}$ & $d ; A$ & $\sigma^{2}\left(\AA^{2}\right)^{b}$ & $\Delta E_{0}(e V)^{c}$ \\
\hline \multicolumn{5}{|c|}{ Mo1-INIT, R= 0.25 } \\
\hline $\mathrm{O}$ & $2.0(3)$ & $1.72(2)$ & $0.005(1)$ & $0(1)$ \\
\hline $\mathrm{O}$ & $2.4(5)$ & $1.94(2)$ & $0.005(1)$ & $0(1)$ \\
\hline Mo & $1.6(5)$ & $3.29(2)$ & $0.0045(5)$ & $-2(2)$ \\
\hline \multicolumn{5}{|c|}{ Mo1-SULF, R= 0.24 } \\
\hline $\mathrm{O}$ & $0.9(2)$ & $1.72(2)$ & $0.004(1)$ & $-1(1)$ \\
\hline $\mathrm{O}$ & $1.4(2)$ & $1.92(1)$ & $0.005(1)$ & $0(1)$ \\
\hline $\mathrm{S}$ & $1.4(2)$ & $2.42(2)$ & $0.005(1)$ & $-1(2)$ \\
\hline Mo & $0.9(3)$ & $3.29(3)$ & $0.005(1)$ & $-5(2)$ \\
\hline \multicolumn{5}{|c|}{ Mo1-HDS, $R=0.22$} \\
\hline $\mathrm{O}$ & $0.8(3)$ & $1.69(2)$ & $0.005(1)$ & $-1(1)$ \\
\hline $\mathrm{O}$ & $1.6(3)$ & $1.94(2)$ & $0.005(1)$ & $-2(2)$ \\
\hline $\mathrm{S}$ & $1.5(2)$ & $2.41(1)$ & $0.005(1)$ & $-2(1)$ \\
\hline Mo & $0.7(3)$ & $3.28(3)$ & $0.0045(5)$ & $-4(2)$ \\
\hline \multicolumn{5}{|c|}{ Mo2-INIT, R=0.15 } \\
\hline $\mathrm{O}$ & $0.9(2)$ & $1.72(1)$ & $0.004(1)$ & $-2(2)$ \\
\hline $\mathrm{O}$ & $2.9(2)$ & $1.95(3)$ & $0.005(1)$ & $0(2)$ \\
\hline $\mathrm{S}$ & $0.8(3)$ & $2.48(4)$ & $0.006(1)$ & $-5(2)$ \\
\hline Mo & $1.5(2)$ & $3.32(3)$ & $0.0045(5)$ & $-3(2)$ \\
\hline \multicolumn{5}{|c|}{ Mo2-SULF, $\mathrm{R}=0.08$} \\
\hline $\mathrm{O}$ & $0.7(2)$ & $1.70(1)$ & $0.006(1)$ & $-3(2)$ \\
\hline $\mathrm{O}$ & $1.8(2)$ & $1.94(2)$ & $0.0035(5)$ & $-1(2)$ \\
\hline $\mathrm{S}$ & $1.5(3)$ & $2.41(2)$ & $0.006(1)$ & $-5(2)$ \\
\hline Mo & $0.7(2)$ & $3.28(3)$ & $0.0040(5)$ & $-4(2)$ \\
\hline \multicolumn{5}{|c|}{ Mo2-HDS, R=0.09 } \\
\hline $\mathrm{O}$ & $2.3(2)$ & $1.72(1)$ & $0.005(1)$ & $-2(2)$ \\
\hline $\mathrm{O}$ & $1.0(2)$ & $1.95(2)$ & $0.0030(5)$ & $-1(2)$ \\
\hline $\mathrm{S}$ & $1.2(3)$ & $2.42(4)$ & $0.007(1)$ & $-4(2)$ \\
\hline Mo & $1.2(2)$ & $3.30(3)$ & $0.0045(5)$ & $-3(2)$ \\
\hline \multicolumn{5}{|c|}{ Mo3-INIT, R=0.12 } \\
\hline $\mathrm{O}$ & $1.3(3)$ & $1.71(1)$ & $0.005(1)$ & $-3(2)$ \\
\hline $\mathrm{S}$ & $2.6(3)$ & $2.41(2)$ & $0.006(1)$ & $-3(2)$ \\
\hline Mo & $0.9(2)$ & $2.73(1)$ & $0.0035(5)$ & $-4(2)$ \\
\hline Mo & $0.5(1)$ & $3.28(3)$ & $0.005(1)$ & $-5(2)$ \\
\hline \multicolumn{5}{|c|}{ Mo3-SULF, $R=0.22$} \\
\hline $\mathrm{O}$ & $0.8(3)$ & $1.69(2)$ & $0.004(1)$ & $-4(2)$ \\
\hline $\mathrm{S}$ & $2.5(3)$ & $2.41(2)$ & $0.005(1)$ & $-5(2)$ \\
\hline Mo & $0.5(1)$ & $3.16(1)$ & $0.005(1)$ & $-2(2)$ \\
\hline Mo & $0.6(1)$ & $3.24(3)$ & $0.006(1)$ & $-4(2)$ \\
\hline \multicolumn{5}{|c|}{ Mo3-HDS, $\mathrm{R}=0.17$} \\
\hline $\mathrm{O}$ & $0.8(3)$ & $1.69(2)$ & $0.004(1)$ & $-3(2)$ \\
\hline $\mathrm{S}$ & $2.1(3)$ & $2.41(2)$ & $0.005(1)$ & $-5(2)$ \\
\hline Mo & $1.0(2)$ & $3.27(3)$ & $0.005(1)$ & $-2(2)$ \\
\hline
\end{tabular}

The attribution of the FT EXAFS peaks to the corresponding elements (Table 1) has been checked using wavelet transform (WT) maps. In the Mo1-INIT and Mo2-INIT samples 
the first peak attributed to oxygen gives WT spots centered at $k$ near $7 \AA^{-1}$, whereas the spot centered at $k$ above $10 \AA^{-1}$, corresponds to molybdenum (Fig. S9a and S10a). After sulfidation, an intermediate WT spot appears at $k$ between 8 and $9 \AA^{-1}$, which corresponds to the sulfur neighbor (Fig S9b and S10b). Therefore, in the Mo1-SULF and Mo2-SULF samples, molybdenum is present in a mixed oxygen-sulfur environment. By contrast, sulfur is the major element in the Mo coordination sphere for the Mo3-INIT sample (Fig S11a). After sulfidation, the relative intensity of the sulfur spot increases whereas the intensity of the molybdenum WT spot decreases, in agreement with the EXAFS fitting results (Table 1).

In order to go deeper in the evaluation of the composition of samples, PCA was also carried out for the set of nine EXAFS spectra (Fig. S12). Four components are needed to explain ca $98 \%$ of total EXAFS spectra information, the fifth and following eigenvectors accounting for noise. Considering the XANES analysis and insights obtained from XAS fitting results, the Mo1-INIT sample was used for accounting the oxidic contribution. Among the different spectra of oxysulfide species used in the LCF [58], the one of the dimeric $\left[\mathrm{Mo}_{2} \mathrm{O}_{2} \mathrm{~S}_{2}\left(\mathrm{~S}_{2}\right)_{2}\right]^{2-}$ anions [59] was found as a standard reproducing satisfactorily the mixed oxygen-sulfur environment. Finally, as the presence of bulk $\mathrm{MoS}_{2}$ has been refuted from microscopy and XANES LCF, we have considered as candidates for fully sulfided species, the trimeric $\left(\mathrm{NH}_{4}\right)_{2} \mathrm{Mo}_{3} \mathrm{~S}_{13}$ precursor and a conventional alumina supported HDS catalyst prepared by industrial liquid sulfidation [56]. The average slab length distribution determined by TEM for this conventional catalyst was centered around $2.9(1.0) \mathrm{nm}$ which is longer than the few $\mathrm{MoS}_{2}$ slabs observed in Fig. 1 for Mo3-SULF and larger than the sizes of few-atom clusters characterizing the samples studied herein. The overall effect on the EXAFS oscillations when the size of slabs is decreasing is a general damping of the EXAFS amplitude due to the reduction of mean coordination numbers. This effect has been mimicked by using the EXAFS spectrum of the conventional alumina supported HDS catalyst recorded at $350{ }^{\circ} \mathrm{C}$. The results of the best linear combination fittings are presented in Fig. S13 and gathered in Table S5. In agreement with the PCA performed for the EXAFS data set, only 4 components contribute significantly to reproduce the EXAFS spectra of the samples with 48 to $88 \%$ of the oxidic species, 12 to $41 \%$ of $\mathrm{MoS}_{2}$ or $\mathrm{Mo}_{3} \mathrm{~S}_{13}$-like species, and $16 \%$ of the $\left[\mathrm{Mo}_{2} \mathrm{O}_{2} \mathrm{~S}_{2}\left(\mathrm{~S}_{2}\right)_{2}\right]^{2-}$ oxysulfide anion for Mo3-INIT. For most samples two components are sufficient to describe the spectra and three components are required for Mo3-INIT (Table S5). Overall, XAS demonstrates that the chemical behavior of ultradispersed Mo species is different from that in highly loaded conventional catalysts. Atomically dispersed thiomolybdate species supported on S-AC are prone to be oxidized in ambient air, whereas their sulfidation-reduction with $\mathrm{H}_{2} \mathrm{~S} / \mathrm{H}_{2}$ at $350{ }^{\circ} \mathrm{C}$ is always partial, i.e. it seems to be more difficult 
than in the conventional systems. Furthermore, XAS proves that the $\mathrm{MoS}_{2}$ phase is not a major component after sulfidation. According to EXAFS LCF, the amount of $\mathrm{MoS}_{2}$ species in our samples never exceeds $40 \%$, the rest being oxide and oxysulfide species. EXAFS alone does not allow distinguishing between small (1-2 nm) $\mathrm{MoS}_{2}$ slabs and several-atom atomically dispersed $\mathrm{Mo}_{\mathrm{x}} \mathrm{S}_{\mathrm{y}}$ clusters that probably involve similar Mo-S and Mo-Mo distances. Conceptually, there is no sharp dividing line between the small slabs and few-atom clusters. For a $2 \mathrm{D}$ material which $\mathrm{MoS}_{2}$ is, the notion of atomic dispersion implies that a flat cluster structure should not contain interior Mo atoms. It could be formally stated then, that the smallest number of Mo atoms in a 2D cluster to have an interior (i.e. to be recognized as a slab with the edges) is ten atoms for a triangular shape and seven atoms for a hexagonal one. However, in practice mostly irregular clusters are observed by STEM, without any evidence that such several-atom clusters have the same geometry as pieces of flat $2 \mathrm{D} \mathrm{MoS}_{2}$ slabs. Noteworthy, since ultradispersed species are systematically observed by STEM in the conventional highly dispersed $\mathrm{MoS}_{2}$-based catalysts, then the EXAFS attributions carried out in the earlier works must have implicitly merged the (greater or lesser) contributions from such species to the main $\mathrm{MoS}_{2}$ signal. With this respect the previously debated discrepancies between the slabs size estimated from EXAFS and TEM [60, 61, 62] obtain a straightforward explanation.

\subsection{XPS analysis}

The oxidation states of Mo and S in three selected samples Mo1-INIT, Mo1-SULF and Mo3-SULF were further investigated by XPS. Sulfur doped carbon support was also investigated by XPS as a reference. In the XPS spectra of all samples, deconvolution of the spin orbit doublet S 2p gives four components (Fig. 3b, d, f). At the lowest energies, a small signal with peaks $\mathrm{S} 2 \mathrm{p}_{3 / 2}$ at $161.9 \mathrm{eV}$ and $\mathrm{S} 2 \mathrm{p}_{1 / 2}$ at $163.1 \mathrm{eV}$ was observed, corresponding to thiol (SH) groups [63]. The major signal at $\mathrm{S} 2 \mathrm{p}_{3 / 2} 163.8 \mathrm{eV}$ and $\mathrm{S} 2 \mathrm{p}_{1 / 2}$ at $165.1 \mathrm{eV}$ might be assigned to the C-S-C bond of thiophene-like sulfur according to Ref. [64]. Other two doublets at higher energies (166.8 eV and $168 \mathrm{eV} ; 169.5 \mathrm{eV}$ and $170.7 \mathrm{eV}$ respectively) represent oxidized sulfur species such as sulfate or sulfite [55, 65]. The XPS spectrum of the bare S-AC support is similar to the spectra of the Mo samples, and it contains the same thiophenic doublet and a low amount of oxidized sulfur as the Mo-containing samples (Fig. S14). Therefore, the contribution to the S 2 p signal coming from the molybdenum (oxy)sulfide species $(0.5-1 \% \mathrm{wt}$. of Mo) is relatively 
small (8\% wt. of S) as compared with that of S-AC sulfur, the majority of the signal coming from the latter.

The interpretation of the Mo $3 \mathrm{~d}$ signal is more difficult than usual for $\mathrm{MoS}_{2}$-based catalysts due to overlapping with a strong S 2 s signal coming from the abundant S species at the surface of S-AC. In the spectrum of Mo1-INIT two doublets Mo $3 \mathrm{~d}_{5 / 2}$ at 232.3 and Mo $3 \mathrm{~d}_{3 / 2}$ at $235.5 \mathrm{eV}$ and other at Mo $3 \mathrm{~d}_{5 / 2}$ at 230.0, Mo $3 \mathrm{~d}_{3 / 2}$ at $232.9 \mathrm{eV}$ were observed. The doublet with the highest energy can be assigned to Mo(VI) in the oxidic environment, usually observed in $\mathrm{MoO}_{3}$ [66]. The second doublet corresponds to $\mathrm{Mo}(\mathrm{V})$, which has been attributed to the oxysulfide [67]. After sulfidation of Mo1-INIT, a shift by $0.7 \mathrm{eV}$ of the Mo(VI) doublet occurs towards lower energies, indicating that reduction occurs and /or oxygen in the Mo coordination environment is partly replaced by sulfur. The contribution of Mo(VI) species becomes smaller (Fig. 3a and 3c). The doublet at 229.2 and $232.4 \mathrm{eV}$ can be attributed to sulfided Mo(IV) [58]. The XPS spectrum of Mo 3d in Mo3-SULF contains contributions of the same species as in Mo1-SULF. However, the contribution of Mo(VI) is much lower than that of Mo(IV). 

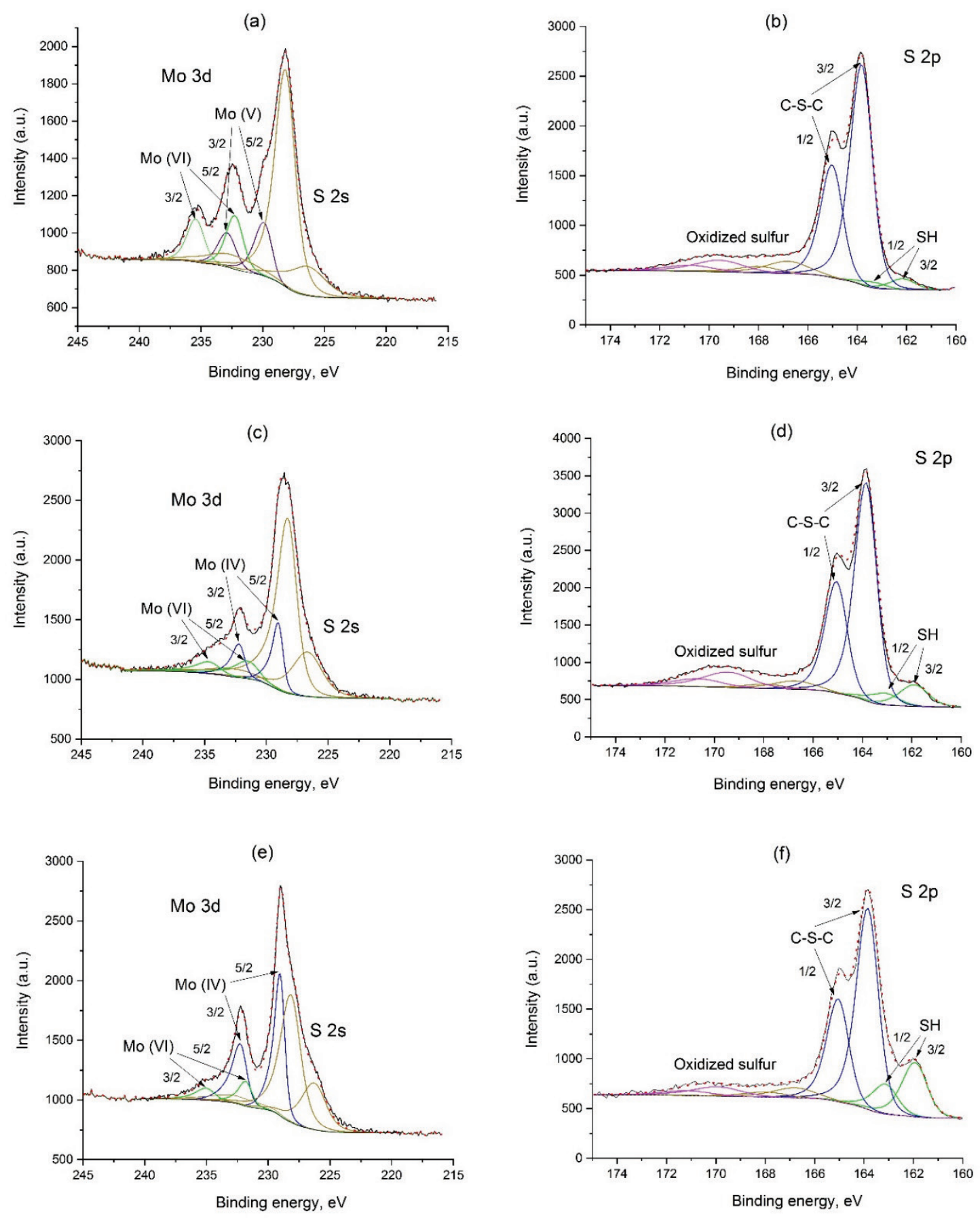

Figure 3 XPS spectra of Mo 3d (a, c, e) for Mo1-INIT (a), Mo1-SULF (c), Mo3-SULF (e) and of S 2p (b, d, f) for Mo1-INIT (b), Mo1-SULF (d), Mo3-SULF (f).

The XPS results indicate that in the Mo1 solid molybdenum is present in a mixed oxygen-sulfur environment even after sulfidation. By contrast, in the Mo3-SULF sample, majority of Mo species is sulfided. This conclusion is in a good agreement with the XAS results. 
In summary, the ensemble of characterizations provides a coherent picture. In the initial samples obtained by adsorption, thiomolybdates are not preserved (against our initial expectations) but undergo a deep chemical transformation. Mono- and dithiomolybdates are fully transformed to $\mathrm{Mo}(\mathrm{V})-\mathrm{Mo}(\mathrm{VI})$ oxospecies, whereas trithiomolybdate is partially preserved as sulfide species. Since the solutions of the corresponding thiosalts are stable in air on the timespans used for our preparations, the oxidative transformation occurs probably with the participation of oxygenated groups remaining at the surface of activated carbon. After sulfidation, mixed oxygen- and sulfur-bearing atomically dispersed Mo species are obtained, which consist of mostly single atoms and/or few-atom clusters, yet according to XAS up to one third of the total molybdenum might be present as $\mathrm{MoS}_{2}$-like structures.

\subsection{Thiophene $H D S$}

Thiophene HDS steady-state specific rates are shown in Fig. $4 \mathrm{a}$ and Table 2 in comparison with benchmark alumina-supported reference [68]. For atomically dispersed species, the values of TOF and specific rate per TM atom are equivalent. The obtained TOF values are 2-3 times higher than the specific activity of the conventional catalyst per Mo atom, attesting high specific activity of ultradispersed Mo species. Bare S-AC did not show any detectable HDS activity.

The three Mo-SULF samples possess somewhat different catalytic behavior in thiophene HDS (Fig. S15a). In addition, the Mo1-INIT sample sulfided in pure $\mathrm{H}_{2} \mathrm{~S}$, designated as Mo1-SULF $\left(\mathrm{H}_{2} \mathrm{~S}\right)$ demonstrated higher activity and stability than the other three samples sulfided in $\mathrm{H}_{2} \mathrm{~S} / \mathrm{H}_{2}$ mixture, probably due to higher sulfidation degree, as discussed previously for bulk $\mathrm{MoS}_{2}$ catalysts [69]. The HDS activity follows the pattern: Mo1-SULF $\left(\mathrm{H}_{2} \mathrm{~S}\right)>\mathrm{Mo1}-$ $\mathrm{SULF} \approx \mathrm{Mo2}-\mathrm{SULF}>\mathrm{Mo3}-\mathrm{SULF}$.

For Mo1-SULF, Mo1-SULF $\left(\mathrm{H}_{2} \mathrm{~S}\right)$ and Mo3-SULF catalysts, the HDS rate rapidly settles down at $320{ }^{\circ} \mathrm{C}$, the initial conversion being much higher (approximately $2.0 \%$ for the first two and $2.6 \%$ for Mo3-SULF) than the steady-state one after $13 \mathrm{~h}$ on stream (Fig. S15b). Mo2-SULF demonstrates lesser difference between the initial conversion and the steady-state one (Fig. S15b). The selectivity of ultradispersed Mo catalysts substantially differs from that of the $\mathrm{MoS}_{2} / \mathrm{Al}_{2} \mathrm{O}_{3}$ reference. Indeed, light products $(\mathrm{C} 1-\mathrm{C} 3)$ are present at the steady state for Mo1-SULF and Mo2-SULF (Fig. S16a-b). Lower amounts of these products are observed in case of Mo2-SULF when compared with Mo1-SULF, which indicates that monothiomolybdatederived samples contain more acidic sites, since the formation of light hydrocarbons probably 
occurs due to hydrocracking on acidic sites. Such an acidity could appear due to the presence of $\mathrm{Mo}=\mathrm{O}$ moieties in the incompletely sulfided Mo clusters, as evidenced by XAS.

To illustrate the appearance of the acidic sites due to Mo species, we tested the acidity of S-AC and Mo1-SULF by means of temperature-programmed desorption (TPD) of $\mathrm{NH}_{3}$. The low-temperature desorption peak centered at $200{ }^{\circ} \mathrm{C}$ might be attributed to weak acidic sites (Fig. S17). In the case of S-AC, only weak acidic sites were detected. For the Mo-containing sample, the area of the first peak increases and it becomes skewed to the higher temperatures. At the same time, an additional peak appears above $400{ }^{\circ} \mathrm{C}$, which can be attributed to medium acidic sites. The calculated amounts of desorbed $\mathrm{NH}_{3}$ for $\mathrm{S}-\mathrm{AC}$ and Mo1-SULF are $11 \mu \mathrm{mol} / \mathrm{g}$ and $40 \mu \mathrm{mol} / \mathrm{g}$, respectively. The difference in the amount of acidic sites between bare S-AC and Mo1-SULF is comparable to the total amount of introduced molybdenum ( $52 \mu \mathrm{mol} / \mathrm{g}$ of Mo in the Mo1-SULF sample).

Remarkably, ultradispersed oxysulfide species persist during sulfidation by $\mathrm{H}_{2} \mathrm{~S} / \mathrm{H}_{2}$ and further HDS process. For conventional catalysts, light hydrocarbons (mostly methane) are sometimes detected in the beginning of the thiophene HDS run, their presence signifying that the catalyst is undersulfided or slightly oxidized at the surface. However, these products quickly disappear during the settling down of activity, due to sulfidation of Mo oxospecies by the feed. By contrast, for Mo1-SULF, light hydrocarbons are observed throughout the catalytic run. However, light products are beyond the detection limit in the case of Mo3-SULF (Fig. S16c) for which, according to XAS, the amount of such oxygen-bearing clusters is lower. Noteworthily, light products are present even for Mo1-SULF $\left(\mathrm{H}_{2} \mathrm{~S}\right)$ (Fig. S16d), suggesting that even sulfidation in pure $\mathrm{H}_{2} \mathrm{~S}$ might be insufficient for complete sulfidation of oxygencontaining Mo species.

During the HDS test at increased reaction temperature $\left(340^{\circ} \mathrm{C}\right)$ the amounts of $\mathrm{C} 1-\mathrm{C} 3$ hydrocracking products decrease for both Mo1-SULF and Mo2-SULF. Perhaps, during the HDS reaction, partially oxidized Mo dimeric species are further sulfided and the amount of $[\mathrm{Mo}=\mathrm{O}]$ acidic sites decreases. To confirm this hypothesis and to determine the evolution of the Mo species under reaction conditions, an additional operando XAS study is necessary. Beside $\mathrm{C} 1-\mathrm{C} 3$ hydrocarbons, butane and butenes are formed as major reaction products, in the proportions similar to those observed for the alumina-supported reference (Fig. S16e).

The observed differences in HDS activity and selectivity might be related to the nature of used precursors. For the sample prepared from $\mathrm{Mo}_{3} \mathrm{~S}_{13}{ }^{2-}$ XAS suggests deeper sulfidation and only HDS products are observed. On the other hand, $\mathrm{Mo}_{2} \mathrm{~S}_{12}{ }^{2-}$ and $\mathrm{MoS}_{4}{ }^{2-}$ precursors lead to partially oxidized oligomers that not only catalyze HDS, but due to their acidity also produce 
light hydrocarbons. Overall, herein we evidence that ultradispersed sulfide Mo catalysts that do not contain TEM-observable $\mathrm{MoS}_{2}$ slabs are able to demonstrate high specific HDS activity.

Though this work is focused on the catalysts containing solely Mo, we also prepared Co-promoted catalysts and tested them in HDS, without going into a detailed study of their physical properties. HDS tests of Co-promoted samples should be regarded here as an additional characterization, revealing the properties of ultradispersed Mo clusters. A detailed study (XAS, XPS) of Co coordination is in view. Addition of Co results in a drastic increase of the catalytic activity. While for the monometallic Mo and Co systems, thiophene steady-state conversions do not exceed $2 \%$, under the same conditions the steady-state conversion reaches $17 \%$ at 320 ${ }^{\circ} \mathrm{C}$ on Co-Mo1-SULF and 14\% on Co-Mo3-SULF (Fig. 4b). The higher activity of Co-Mo1SULF in comparison with Co-Mo3-SULF correlates with the higher initial activity of the corresponding non-promoted Mo1-SULF vs. Mo3-SULF (Fig. S15a). Thus, it can be concluded that promotion with cobalt occurs for our systems at least as efficiently as for the conventional $\mathrm{MoS}_{2}$ catalysts [42]. In the previous literature, bulk $\mathrm{Co}_{9} \mathrm{~S}_{8}$ phase formed upon sulfidation and HDS test was considered to possess low activity in HDS [20]. However, if prepared in the highly dispersed state, $\mathrm{Co}_{9} \mathrm{~S}_{8}$ shows HDS activity comparable to that of $\mathrm{MoS}_{2}$ [70]. The CoSULF reference catalyst demonstrates a significant activity, comparable to that of Mo1-Mo3 systems, perhaps because it contains Co sulfide species active in the ultradispersed state. For Co-promoted samples, the relative amounts of light hydrocarbons are low (below 1\%), butane and butenes being the major products (Fig. S18). Indeed, promotion of molybdenum HDS sites with cobalt efficiently occurs, but it is obviously not the case for the acidic sites.
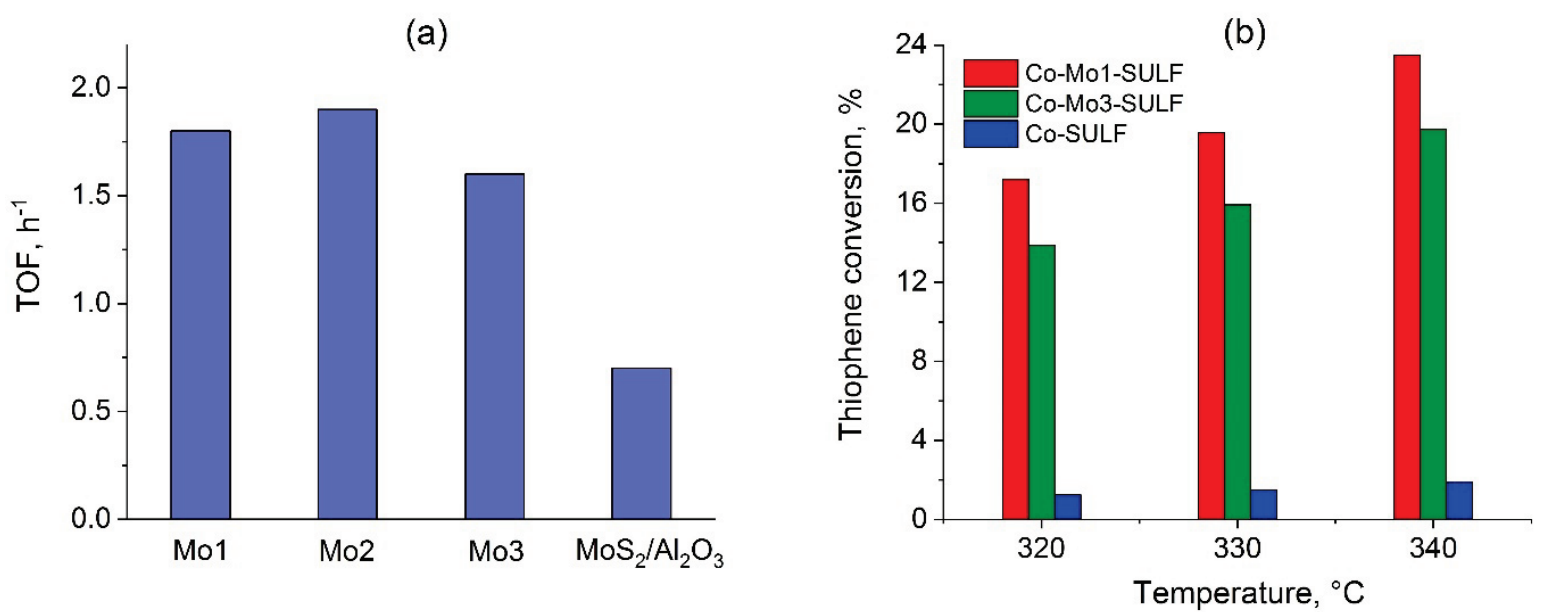

Figure 4 (a) TOF values for Mo1-SULF, Mo2-SULF, Mo3-SULF and reference $\mathrm{MoS}_{2} / \mathrm{Al}_{2} \mathrm{O}_{3}$ at 320 ${ }^{\circ} \mathrm{C}$; (b) Thiophene conversion versus temperature for Co-containing samples. 
Table 2 Molybdenum loadings, specific thiophene HDS rates and TOF values measured at $320{ }^{\circ} \mathrm{C}$ for three ultradispersed Mo catalysts and a $\mathrm{MoS}_{2} / \mathrm{Al}_{2} \mathrm{O}_{3}$ reference.

\begin{tabular}{|c|c|c|c|c|}
\hline Catalyst & \%Mo wt. & $\begin{array}{l}\text { Thiophene } \\
\text { conversion \% }\end{array}$ & $\begin{array}{l}\text { Specific rate } \\
10^{-8} \mathrm{~mol} \cdot \mathrm{g}^{-1} \mathrm{~s}^{-1}\end{array}$ & $\mathrm{TOF} \mathrm{h}^{-1}$ \\
\hline Mo1-SULF & 0.5 & 0.63 & 2.6 & 1.81 \\
\hline Mo1-SULF $\mathrm{H}_{2} \mathrm{~S}$ & 0.5 & 0.77 & 3.3 & 2.30 \\
\hline Mo2-SULF & 0.5 & 0.65 & 2.7 & 1.89 \\
\hline Mo3-SULF & 0.5 & 0.56 & 2.3 & 1.63 \\
\hline $\mathrm{MoS}_{2} / \mathrm{Al}_{2} \mathrm{O}_{3}$ & 10 & 4.5 & 19.5 & $0.67^{\mathrm{a}}$ \\
\hline
\end{tabular}

${ }^{\mathrm{a}}$ specific activity per Mo atom

\section{Conclusions}

The main finding of this work is that ultrasmall sulfide or oxysulfide Mo clusters demonstrate high HDS activity and can be promoted with cobalt at least as efficiently as the $\mathrm{MoS}_{2}$ edges in conventional catalysts. Such ultrasmall clusters cannot be regarded as edges of the $\mathrm{MoS}_{2}$ slabs. As the atomically dispersed catalysts have been obtained by common sulfidation procedures, they might be present in other $\mathrm{MoS}_{2}$-based catalysts, coexisting there with nanoscopic $\mathrm{MoS}_{2}$ slabs. Therefore, ultradispersed species invisible by TEM should not be neglected in the interpretations of the activity trends of(conventional) $\mathrm{MoS}_{2}$-based catalysts. The conclusions of previous works relating the catalytic activity to the TEM-observable shape and size of $\mathrm{MoS}_{2}$ particles should probably be revisited from this viewpoint. For example, strong variations in $\mathrm{MoS}_{2} / \mathrm{Al}_{2} \mathrm{O}_{3}$ HDS activity observed without a comparable evolution of the slabs size [36] could be explained by agglomeration of TEM-invisible ultradispersed species.

There are still many questions remaining unanswered. For example, we ignore how many Mo atoms should be present in a cluster to possess HDS activity and through what type of bonding these species are anchored onto the carbon surface. Further studies (operando XAS, adsorption of probe molecules, theoretical calculations) are planned to understand the structure and stability of such species.

The potential of ultradispersed sulfide clusters is obviously not limited to the hydrotreating applications. Thiophene HDS is one of the simplest model reactions to assess any novel sulfide catalyst. However, the scope of potential applications might be extended to other reactions, where $\mathrm{MoS}_{2}$ or sulfides of other metals are efficient. 


\section{Acknowledgements:}

The XAS work was supported by a public grant overseen by the French National Research Agency (ANR) as a part of the "Investissements d'Avenir" (ref: ANR-10-EQPX-45) provided for the building of the ROCK beamline.

\section{References}

1. G. Centi, S. Perathoner, Catalysis: Role and Challenges for a Sustainable Energy, Top. Catal. 52 (2009) 948-961. 10.1007/s11244-009-9245-x;

2. J. Liu, Single-Atom Catalysis for a Sustainable and Greener Future, Curr. Opin. Green Sustain. Chem. 22 (2020) 54-64. https://doi.org/10.1016/j.cogsc.2020.01.004;

3. H. Li, H. Zhu, Z. Zhuang, S. Lu, F. Duan, M. Du, Single-atom catalysts for electrochemical clean energy conversion: recent progress and perspectives, Sustain. Energy Fuels. 4 (2020) 996-1011. https://doi.org/10.1039/C9SE01004A;

4. X.-F. Yang, A. Wang, B. Qiao, J. Li, J. Liu, T. Zhang, Single-Atom Catalysts: A New Frontier in Heterogeneous Catalysis, Acc. Chem. Res. 46 (2013) 1740-1748.

https://doi.org/10.1021/ar300361m;

5. W. Ma, J. Mao, X. Yang, C. Pan, W. Chen, M. Wang, P. Yu, L. Mao, Y. Li, A single-atom $\mathrm{Fe}-\mathrm{N}_{4}$ catalytic site mimicking bifunctional antioxidative enzymes for oxidative stress cytoprotection, Chem. Commun. 55 (2019) 159-162. https://doi.org/10.1039/C8CC08116F; 6. R. Xiao, K. Chen, X. Zhang, Z. Yang, G. Hu, Z. Sun, H.-M. Cheng, F. Li, Single-atom catalysts for metal-sulfur batteries: Current progress and future perspectives, J. Energy Chem. 54 (2021) 452-466. https://doi.org/10.1016/j.jechem.2020.06.018.

7. Y. Xue, B. Huang, Y. Yi, Y. Guo, Z. Zuo, Y. Li, Z. Jia, H. Liu, Y. Li, Anchoring zero valence single atoms of nickel and iron on graphdiyne for hydrogen evolution, Nat. Commun. 9 (2018) 1460. https://doi.org/10.1038/s41467-018-03896-4.

8. A. Wang, J. Li, T. Zhang, Heterogeneous single-atom catalysis, Nat. Rev. Chem. 2 (2018) 65-81. https://doi.org/10.1038/s41570-018-0010-1.

9. N. Cheng, S. Stambula, D. Wang, M.N. Banis, J. Liu, A. Riese, B. Xiao, R. Li, T.-K. Sham, L.-M. Liu, G.A. Botton, X. Sun, Platinum single-atom and cluster catalysis of the hydrogen evolution reaction, Nat. Commun. 7 (2016) 13638. https://doi.org/10.1038/ncomms13638; 10. J. Ji, Y. Zhang, L. Tang, C. Liu, X. Gao, M. Sun, J. Zheng, M. Ling, C. Liang, Z. Lin, Platinum single-atom and cluster anchored on functionalized MWCNTs with ultrahigh mass 
efficiency for electrocatalytic hydrogen evolution, Nano Energy. 63 (2019) 103849. https://doi.org/10.1016/j.nanoen.2019.06.045;

11. C.H. Choi, M. Kim, H.C. Kwon, S.J. Cho, S. Yun, H.-T. Kim, K.J.J. Mayrhofer, H. Kim, M. Choi, Tuning selectivity of electrochemical reactions by atomically dispersed platinum catalyst, Nat. Commun. 7 (2016) 10922. https://doi.org/10.1038/ncomms10922;

12. L. Wang, M.-X. Chen, Q.-Q. Yan, S.-L. Xu, S.-Q. Chu, P. Chen, Y. Lin, H.-W. Liang, A sulfur-tethering synthesis strategy toward high-loading atomically dispersed noble metal catalysts, Sci. Adv. 5 (2019) eaax6322. https://doi.org/10.1126/sciadv.aax6322;

13. J. Haber. Moybdenum compounds in Heterogeneous Catalysis, Studies in Inorganic Chemistry. 19 (1994) 477-617. https://doi.org/10.1016/B978-0-444-88198-4.50015-2;

14. D.J. Sajkowski, S.T. Oyama. Catalytic hydrotreating by molybdenum carbide and nitide: unsupported $\mathrm{Mo}_{2} \mathrm{~N}$ and $\mathrm{Mo}_{2} \mathrm{CAl}_{2} \mathrm{O}_{3}$, Appl. Catal. A: Gen. 134 (1996) 339-349.

https://doi.org/10.1016/0926-860X(95)00202-2;

15. G.S. Ranhotra, A.T. Bell, J.A. Reimer, Catalysis over molybdenum carbides and nitrides: II. Studies of CO hydrogenation and $\mathrm{C}_{2} \mathrm{H}_{6}$ hydrogenolysis, J. Catal. 108 (1987) 40-49. https://doi.org/10.1016/0021-9517(87)90153-9;

16. P. Afanasiev, Synthetic approaches to the molybdenum sulfide materials, C. R. Chim. 11 (2008) 159-182. https://doi.org/10.1016/j.crci.2007.04.009;

17. Q. Ding, B. Song, P. Xu, S. Jin, Efficient Electrocatalytic and Photoelectrochemical Hydrogen Generation Using $\mathrm{MoS}_{2}$ and Related Compounds, Chem. 1 (2016) 699-726. https://doi.org/10.1016/j.chempr.2016.10.007.

18. J. Bonde, P.G. Moses, T.F. Jaramillo, J.K. Nørskov, I. Chorkendorff, Hydrogen evolution on nano-particulate transition metal sulfides, Faraday Discuss. 140 (2009) 219-231. https://doi.org/10.1039/B803857K;

19. U. Gupta, C.N.R. Rao, Hydrogen generation by water splitting using MoS2 and other transition metal dichalcogenides, Nano Energy. 41 (2017) 49-65.

https://doi.org/10.1016/j.nanoen.2017.08.021.

20. H. Topsøe, B.S. Clausen, F.E. Massoth, Hydrotreating Catalysis, in J.R. Anderson, M. Boudart (Eds.), Catalysis-Science and Technology, Springer, Berlin, Heidelberg, 1996, pp. 1269.

21. A. Stanislaus, A. Marafi, M.S. Rana, Recent advances in the science and technology of ultra low sulfur diesel (ULSD) production, Catal. Today. 153 (2010) 1-68.

https://doi.org/10.1016/j.cattod.2010.05.011; 
22. J.N.D. de León, C.R. Kumar, J. Antúnez-García, S. Fuentes-Moyado, Recent Insights in Transition Metal Sulfide Hydrodesulfurization Catalysts for the Production of Ultra Low Sulfur Diesel: A Short Review, Catalysts. 9 (2019) 87. https://doi.org/10.3390/catal9010087; 23. C. Tang, Y. Jiao, B. Shi, J. Liu, Z. Xie, X. Chen, Q. Zhang, S. Qiao, Coordination Tunes Selectivity: Two-Electron Oxygen Reduction on High-Loading Molybdenum Single-Atom Catalysts, Angew. Chem. 132 (2020) 9256-9261. https://doi.org/10.1002/ange.202003842; 24. C. Wang, D. Wang, S. Liu, P. Jiang, Z. Lin, P. Xu, K. Yang, J. Lu, H. Tong, L. Hu, W. Zhang, Q. Chen, Engineering the coordination environment enables molybdenum single-atom catalyst for efficient oxygen reduction reaction, J. Catal. 389 (2020) 150-156.

https://doi.org/10.1016/j.jcat.2020.05.034;

25. R. Weindl, R. Khare, L. Kovarik, A. Jentys, K. Reuter, H. Shi, J. Lercher, Zeolite stabilized di- and tetranuclear molybdenum sulfide clusters form stable catalytic hydrogenation sites, Angew. Chem. Int. Ed. 60(17) (2021) 9301-9305.

\section{$\underline{10.1002 / \text { anie. } 202015769}$}

26. S. Brunet, D. Mey, G. Pérot, C. Bouchy, F. Diehl, On the hydrodesulfurization of FCC gasoline: a review, Appl. Catal. A: Gen. 278 (2005) 143-172. 10.1016/j.apcata.2004.10.012 27. H. Toulohat, P. Raybaud, Catalysis by transition metal sulphides from molecular theory to industrial application. TECHNIP. (2013), 832.

28. K. Guo, Y. Ding, Z. Yu, One-step synthesis of ultrafine MoNiS and MoCoS monolayers as high-performance catalysts for hydrodesulfurization and hydrodenitrogenation, Appl. Catal. B: Environ. 239 (2018) 433-440. https://doi.org/10.1016/j.apcatb.2018.08.041; 29. A.S. Walton, J.V. Lauritsen, H. Topsøe, F. Besenbacher, $\mathrm{MoS}_{2}$ nanoparticle morphologies in hydrodesulfurization catalysis studied by scanning tunneling microscopy, J. Catal. 308 (2013) 306-318. https://doi.org/10.1016/j.jcat.2013.08.017;

30. S. L. González-Cortés, T.-C. Xiao, P.M.F.J. Costa, B. Fontal, M.L.H. Green, Ureaorganic matrix method: an alternative approach to prepare Co-MoS2 $/ \gamma$-A12O3 HDS catalyst, Applied Catalysis A: General. 270 (2004) 209-222.

https://doi.org/10.1016/j.apcata.2004.05.006.

31. M. Girleanu, S. Lopes Silva, D. Ihiawakrim, A. Chaumonnot, A. Bonduelle-Skrzypczak, F. Lefebvre, V. Dufaud, A.-S. Gay, O. Ersen, HAADF-STEM high-resolution study of nanometric $\mathrm{MoS}_{2}$ inside mesoporous SBA-15, Micropor. Mesopor. Mater. 217 (2015) 190195. https://doi.org/10.1016/j.micromeso.2015.06.021.

32. S.V. Budukva, O.V. Klimov, D.D. Uvarkina, Yu.A. Chesalov, I.P. Prosvirin, T.V. Larina, A.S. Noskov, Effect of citric acid and triethylene glycol addition on the reactivation of 
$\mathrm{CoMo} / \gamma-\mathrm{Al}_{2} \mathrm{O}_{3}$ hydrotreating catalysts, Catal. Today. 329 (2019) 35-43. https://doi.org/10.1016/j.cattod.2018.10.017.

33. L. Zavala-Sanchez, X. Portier, F. Maugé, L. Oliviero, Formation and stability of CoMoS nanoclusters by the addition of citric acid: A study by high resolution STEM-HAADF microscopy, Catal. Today. (2020). https://doi.org/10.1016/j.cattod.2020.10.039;

34. V. Costa, B. Guichard, M. Digne, C. Legens, P. Lecour, K. Marchand, P. Raybaud, E. Krebs, C. Geantet, A rational interpretation of improved catalytic performances of additiveimpregnated dried CoMo hydrotreating catalysts: A combined theoretical and experimental study, Catal. Sci. Technol. 3 (2012) 140-151. https://doi.org/10.1039/C2CY20553J. 35. P. Raybaud, J. Hafner, G. Kresse, S. Kasztelan, H. Toulhoat, Ab Initio Study of the $\mathrm{H}_{2}-$ $\mathrm{H}_{2} \mathrm{~S} / \mathrm{MoS}_{2}$ Gas-Solid Interface: The Nature of the Catalytically Active Sites, J. Catal. 189 (2000) 129-146. https://doi.org/10.1006/jcat.1999.2698.

36. B. Baubet, E. Devers, A. Hugon, E. Leclerc, P. Afanasiev, The influence of $\mathrm{MoS}_{2}$ slab 2D morphology and edge state on the properties of alumina-supported molybdenum sulfide catalysts, Appl. Catal. A: Gen. 487 (2014) 72-81.

https://doi.org/10.1016/j.apcata.2014.09.010;

37. B. Baubet, M. Girleanu, A.-S. Gay, A.-L. Taleb, M. Moreaud, F. Wahl, V. Delattre, E. Devers, A. Hugon, O. Ersen, P. Afanasiev, P. Raybaud, Quantitative Two-Dimensional (2D) Morphology-Selectivity Relationship of CoMoS nanolayers: A Combined High-Resolution High-Angle Annular Dark Field Scanning Transmission Electron Microscopy (HR HAADFSTEM) and Density Functional Theory (DFT) Study, ACS Catal. 6 (2016) 1081-1092. https://doi.org/10.1021/acscatal.5b02628;

38. D. Genuit, P. Afanasiev, M. Vrinat, Solution syntheses of unsupported Co(Ni)-Mo-S hydrotreating catalysts, J. Catal. 235 (2005) 302-317.

https://doi.org/10.1016/j.jcat.2005.08.016;

39. C. Coyle Lee, T.R. Halbert, W.-H. Pan, M.A. Harmer, L. Wei, M.E. Leonowicz, C.O.B. Dim, K.F. Miller, A.E. Bruce, S. McKenna, J.L. Corbin, S. Wherland, E.I. Stiefel, Synthesis, reactivity and redox properties of dinuclear molybdenum-sulfur complexes, Inorganica Chim. Acta. 243 (1996) 147-160. https://doi.org/10.1016/0020-1693(95)04902-9;

40. A. Müller, E. Diemann, A. Branding, F.W. Baumann, New Method for the Preparation of Hydrodesulphurization Catalysts: Use of the Molybdenum Sulphur Cluster Compound $\left(\mathrm{NH}_{4}\right)_{2}\left[\mathrm{Mo}_{3} \mathrm{~S}_{13}\right]$, Appl. Catal. 62 (1990) 13-17. https://doi.org/10.1016/S01669834(00)82228-9; 
41. G. Bofan, H. Weizhuang, Z. Qixiu, A study on separation of molybdenum from tungsten by an adsorption process using activated carbon, Int. J. Refract. Hard Met. 14 (1996) 319323. https://doi.org/10.1016/S0263-4368(96)00021-2;

42. I. Bezverkhyy, P. Afanasiev, M. Lacroix, Promotion of highly loaded $\mathrm{MoS}_{2} / \mathrm{Al}_{2} \mathrm{O}_{3}$ hydrodesulfurization catalysts prepared in aqueous solution, J. Catal. 230 (2005) 133-139. https://doi.org/10.1016/j.jcat.2004.12.009;

43. V. Briois, C. La Fontaine, S. Belin, L. Barthe, T. Moreno, V. Pinty, A. Carcy, R. Girardot, E. Fonda, ROCK: the new Quick-EXAFS beamline at SOLEIL, J. Phys. Conf. Ser. 712 (2016) 012149. 10.1088/1742-6596/712/1/012149;

44. A.L. Ankudinov, B. Ravel, J.J. Rehr, S.D. Conradson, Real-space multiple-scattering calculation and interpretation of x-ray-absorption near-edge structure, Phys. Rev. B. 58 (1998) 7565-7576. https://doi.org/10.1103/PhysRevB.58.7565;

45. K.V. Klementev, Extraction of the fine structure from x-ray absorption spectra, J. Phys. D: Appl. Phys. 34 (2001) 209-217. https://doi.org/10.1088/0022-3727/34/2/309;

46. Y. Chen, S. Ji, C. Chen, Q. Peng, D. Wang, Y. Li, Single-Atom Catalysts: Synthetic Strategies and Electrochemical Applications, Joule. 2 (2018) 1242-1264.

https://doi.org/10.1016/j.joule.2018.06.019;

47. L. Piccolo, Restructuring effects of the chemical environment in metal nanocatalysis and single-atom catalysis, Catal. Today 373 (2021) 80-97.

\section{https://doi.org/10.1016/j.cattod.2020.03.052;}

48. C. Dessal, A. Sangnier, C. Chizallet, C. Dujardin, F. Morfin, J.-L. Rousset, M. Aouine, M. Bugnet, P. Afanasiev, L. Piccolo, Atmosphere-dependent stability and mobility of catalytic Pt single atoms and clusters on $\gamma-\mathrm{Al}_{2} \mathrm{O}_{3}$, Nanoscale. 11 (2019) 6897-6904.

https://doi.org/10.1039/C9NR01641D;

49. K. Al-Dalama, A. Stanislaus, A Comparative Study of the Influence of Chelating Agents on the Hydrodesulfurization (HDS) Activity of Alumina and Silica-Alumina-Supported CoMo Catalysts, Energy Fuels. 20 (2006) 1777-1783. https://doi.org/10.1021/ef060125a; 50. Z. Chen, E. Vorobyeva, S. Mitchell, E. Fako, N. Lopez, S. M. Collins, R. K. Leary, P. A. Midgley, R. Hauert, J. Perez-Ramirez, Single-atom heterogeneous catalysts based on distinct carbon nitride scaffolds Natl. Sci. Rev. 5 (2018) 642-652. 10.1093/nsr/nwy048;

51. Y. Wang, W. Zhang, D. Deng, X. Bao, Two-dimensional materials confining single atoms for catalysis, Chinese J. Catal. 38 (2017) 1443-1453. 10.1016/S1872-2067(17)62839-0;

52. W. Kicinski, M. Szala, M. Bystrzejewski, Sulfur-doped porous carbons: Synthesis and applications, Carbon. 68 (2014) 1-32. http://dx.doi.org/10.1016/j.carbon.2013.11.004; 
53. Y. Liu, X. Liu, W. Dong, L. Zhang, Q. Kong, W. Wang, Efficient Adsorption of Sulfamethazine onto Modified Activated Carbon: A Plausible Adsorption Mechanism, Sci. Rep. 7 (2017) 12437. https://doi.org/10.1038/s41598-017-12805-6;

54. P. Glatzel, U. Bergmann, High resolution 1s core hole X-ray spectroscopy in $3 \mathrm{~d}$ transition metal complexes - electronic and structural information, Coord. Chem. Rev. 249 (2005) 6595. https://doi.org/10.1016/j.ccr.2004.04.011;

55. P. Afanasiev, C. Lorentz, Oxidation of Nanodispersed $\mathrm{MoS}_{2}$ in Ambient Air: The Products and the Mechanistic Steps, J. Phys. Chem. C. 123 (2019) 7486-7494; https://doi.org/10.1021/acs.jpcc.9b01682;

56. C. Lesage, E. Devers, C. Legens, G. Fernandes, O. Roudenko, V. Briois, High pressure cell for edge Jumping X-ray absorption spectroscopy: Applications to industrial liquid sulfidation of hydrotreatment catalysts, Catal. Today. 336 (2019) 63-73.

https://doi.org/10.1016/j.cattod.2019.01.081;

57. A. Rochet, B. Baubet, V. Moizan, E. Devers, A. Hugon, C. Pichon, E. Payen, V. Briois, Intermediate Species Revealed during Sulfidation of Bimetallic Hydrotreating Catalyst: A Multivariate Analysis of Combined Time-Resolved Spectroscopies, J. Phys. Chem. C. 121 (2017) 18544-18556. https://doi.org/10.1021/acs.jpcc.7b03735;

58. L. Plais, Catalyseurs d'hydrotraitement $\mathrm{Mo} / \mathrm{Al}_{2} \mathrm{O}_{3}$ doublement promus prepares à partir d'hétéropolyanions d'Anderson: Suivi de la sulfuration par Quick-EXAFS, PhD thesis, University of Lille, 2017;

59. W. Clegg, N. Mohan, A. Müller, A. Neuman, W. Rittner, G. M. Sheldrick, Crystal and molecular structure of $\left[\mathrm{N}\left(\mathrm{CH}_{3}\right)_{4}\right]_{2}\left[\mathrm{Mo}_{2} \mathrm{O}_{2} \mathrm{~S}_{2}\left(\mathrm{~S}_{2}\right)_{2}\right]$ : a compound with two $\mathrm{S}_{2}{ }^{2-}$ ligands Inorg. Chem. 19 (1980) 2066-2069. https://doi.org/10.1021/ic50209a046;

60. C. Calais, N. Matsubayashi, C. Geantet, Y. Yoshimura, H. Shimada, A. Nishijima, M. Lacroix, M. Breysse, Crystallite Size Determination of Highly Dispersed Unsupported $\mathrm{MoS}_{2}$ Catalysts, J. Catal. 174 (1998) 130-141. https://doi.org/10.1006/jcat.1998.1934;

61. T. Shido, R. Prins, Why EXAFS Underestimated the Size of Small Supported $\mathrm{MoS}_{2}$ Particles, J. Phys. Chem. B. 102 (1998) 8426-8435. https://doi.org/10.1021/jp982322j;

62. H. Shimada, N. Matsubayashi, T. Sato, Y. Yoshimura, M. Imamura, T. Kameoka, A. Nishijima, EXAFS study on the dispersion of molybdenum sulfide catalysts on $\gamma-\mathrm{Al}_{2} \mathrm{O}_{3}$, Catal Lett. 20 (1993) 81-86. https://doi.org/10.1007/BF00772599;

63. F. Buckel, F. Effenberger, C. Yan, A. Gölzhäuser, M. Grunze, Influence of Aromatic Groups Incorporated in Long-Chain Alkanethiol Self-Assembled Monolayers on Gold. Adv. Mater. 12 (2000) 901-905. doi:10.1002/1521-4095(200006)12; 
64. L. Qie, W. Chen, X. Xiong, C. Hu, F. Zou, P. Hu, Y. Huang, Sulfur-Doped Carbon with Enlarged Interlayer Distance as a High-Performance Anode Material for Sodium-Ion Batteries, Adv. Sci. (2015) 1500195. 10.1002/advs.201500195;

65. C.P. Chen, B.L. Ong, S.W. Ong, W. Ong, H.R. Tan, J.W. Chai, Z. Zhang, S.J. Wang, J.S. Pan, L.J. Harrison, H.C. Kang, E.S. Tok, In-situ growth of $\mathrm{HfO}_{2}$ on clean $2 \mathrm{H}-\mathrm{MoS}_{2}$ surface: Growth mode, interface reactions and energy band alignment, Appl. Surf. Sci. 420 (2017) 523-534. 10.1016/j.apsusc.2017.05.097;

66. A.M. de Jong, H.J. Borg, L.J. van IJzendoorn, V.G.F.M. Soudant, V.H.J. de Beer, J.A.R. van Veen, J.W. Niemantsverdriet, Sulfidation mechanism of molybdenum catalysts supported on $\mathrm{SiO}_{2} / \mathrm{Si}(100)$ model support studied by surface spectroscopy. J. Phys. Chem. 97 (1993) 6477-6483. https://doi.org/10.1021/j100126a024;

67. A. Hadj-Aïssa, F. Dassenoy, C. Geantet, P. Afanasiev, Solution synthesis of core-shell Co9 $\mathrm{S}_{8} @ \mathrm{MoS}_{2}$ catalysts. Catal. Sci.\& Technol., 6 (2016) 4901-4909. doi:10.1039/c6cy00311g; 68. P. Afanasiev, Calculation of $\mathrm{MoS}_{2}$ slabs morphology descriptors from transmission electron microscopy data revisited. Case study of the influence of citric acid and treatment conditions on the properties of $\mathrm{MoS}_{2} / \mathrm{Al}_{2} \mathrm{O}_{3}$, Appl. Catal. A: Gen. 529 (2017) 10-19. https://doi.org/10.1016/j.apcata.2016.10.008;

69. P. Afanasiev, The influence of reducing and sulfiding conditions on the properties of unsupported $\mathrm{MoS}_{2}$-based catalysts, J. Catal. 269 (2010) 269-280.

https://doi.org/10.1016/j.jcat.2009.11.004;

70. I. Bezverkhyy, P. Afanasiev, M. Danot, Preparation of Highly Dispersed Pentlandites $\left(\mathrm{M}, \mathrm{M}^{\circ}\right)_{9} \mathrm{~S}_{8}\left(\mathrm{M}, \mathrm{M}^{\star}=\mathrm{Fe}, \mathrm{Co}, \mathrm{Ni}\right)$ and Their Catalytic Properties in Hydrodesulfurization, J. Phys. Chem. B. 108 (2004) 7709-7715. https://doi.org/10.1021/jp049692u. 